\title{
Postpartum Sleep in New Mothers and Fathers
}

\author{
Hawley E. Montgomery-Downs ${ }^{1, *}$, Robyn Stremler ${ }^{2}$ and Salvatore P. Insana ${ }^{3}$ \\ ${ }^{1}$ West Virginia University, Department of Psychology, 53 Campus Drive; PO Box 6040; Morgantown, West Virginia \\ 26506-6040, USA \\ ${ }^{2}$ University of Toronto, Lawrence S. Bloomberg Faculty of Nursing, Toronto, Canada \\ ${ }^{3}$ University of Pittsburgh, Department of Psychiatry, Pittsburgh, PA 15213, USA
}

\begin{abstract}
In this review, we describe postpartum sleep as characterized by marked fragmentation, resulting in nearuniversal fatigue during the initial postpartum period. This sleep disturbance and fatigue are major contributing factors to the onset of affect and mood disturbance, which in turn is strongly associated with an increase in negative infant-parent interactions and adverse infant emotional and cognitive outcomes. Although less-frequently studied, postpartum fathers also experience sleep disturbance and sleepiness associated impairments that impact their families. Despite this, postpartum sleep should be considered a normative developmental period, and the need for intervention can be seen as a byproduct of social and economic expectations that new parents return to the workforce soon after childbirth. Heretofore, there is little evidence to support the efficacy of interventions to improve parent sleep, though some suggest that socially disadvantaged families may benefit most from advice regarding infant and maternal sleep. Also reviewed here is the evidence for a high proportion of children reported to co-sleep with their parents - despite the professional recommendations in the United States - and the need for family education regarding safe co-sleeping. Finally, one obstacle to a woman's decision to breastfeed may be concern about how this will affect her sleep; the evidence for a lack of impact of infant breast feeding on maternal sleep is evident.
\end{abstract}

Keywords: Breastfeeding, bedsharing, co-sleeping, father, fatigue, feeding, infant, intervention, marriage, maternal, mood, mother, paternal, postpartum sleep fragmentation.

\section{SLEEP DEPRIVATION AND SLEEP FRAGME- NTATION}

Partial sleep deprivation erodes cognition, mood, and motor skills [1]. In classic studies, performance decrements became significant after only one night of $<3$ hours of sleep, or two consecutive nights of 5 hours [2]. Indeed, partial deprivation $(\leq 5$ hours) causes greater functional impairment than either short or long-term complete sleep deprivation [3]. Impairment is so great that subjects have become unwilling or unable to continue participation in gradual sleep reduction studies due to their inability to function on less than 5 hours of sleep per night for one month [4].

Sleep fragmentation, distinct from sleep deprivation, is increasingly studied due to its association with the highly prevalent sleep disorders obstructive sleep apnea $[5,6]$ and periodic limb movement disorder [7-9]. In contrast to sleep deprivation, sleep fragmentation causes frequent interruption of sleep architecture throughout the night while generally preserving total sleep time [1]. Consistent with deprivation, fragmentation - whether experimentally induced or the result of a sleep disorder - also leads to excessive daytime sleepiness and decrements in cognitive performance [10,11], executive function [12], and quality of life [13].

*Address correspondence to this author at West Virginia University; Department of Psychology; 53 Campus Drive; PO Box 6040; Morgantown, West Virginia 26506-6040, USA; Phone: (304) 293-1761;

Fax: (304) 293-6606; E-mail: Hawley.Montgomery-Downs@mail.wvu.edu
The theoretical explanation for this cumulative work is that a minimum duration of uninterrupted sleep may be necessary to maximize sleep's neurocognitive benefits $[1,11,14]$.

\section{POSTPARTUM SLEEP FRAGMENTATION}

The issue of sleep fragmentation is relevant to postpartum parents because their sleep is characterized by frequent interruptions. Infant sleep follows a polyphasic pattern, distributed almost equally across the day and night [15] and the infant sleep cycle duration is roughly 50-60 minutes, unlike the approximate 90 minute sleep cycle of older children and adults [16]. There are also large individual differences in infant sleep unrelated to maternal demographic characteristics. Infants from birth to 12 months sleep 6-12 hours/day with an average of 3 nocturnal awakenings (even more in the early months) and napping accounting for $<1$ hour to 6 hours/day. Further, napping may be organized in one prolonged (four hour) nap or up to eight five-minute naps [17]. Thus, adults who must replicate the typical infant sleep pattern end up with highly fragmented sleep.

The cumulative data support a profile of postpartum women's sleep as being characterized by fragmentation, but not necessarily deprivation. Dorheim and colleagues' [18] comparative sample of non-depressed mothers at two months postpartum had total sleep time of 7.8 hours, time in bed was 9.0 hours, and sleep efficiency was $87.6 \%$. Posmontier's [19] sample of non-depressed mothers from 6-26 weeks postpartum had sleep efficiency of $89.2 \%$. Our recent work 

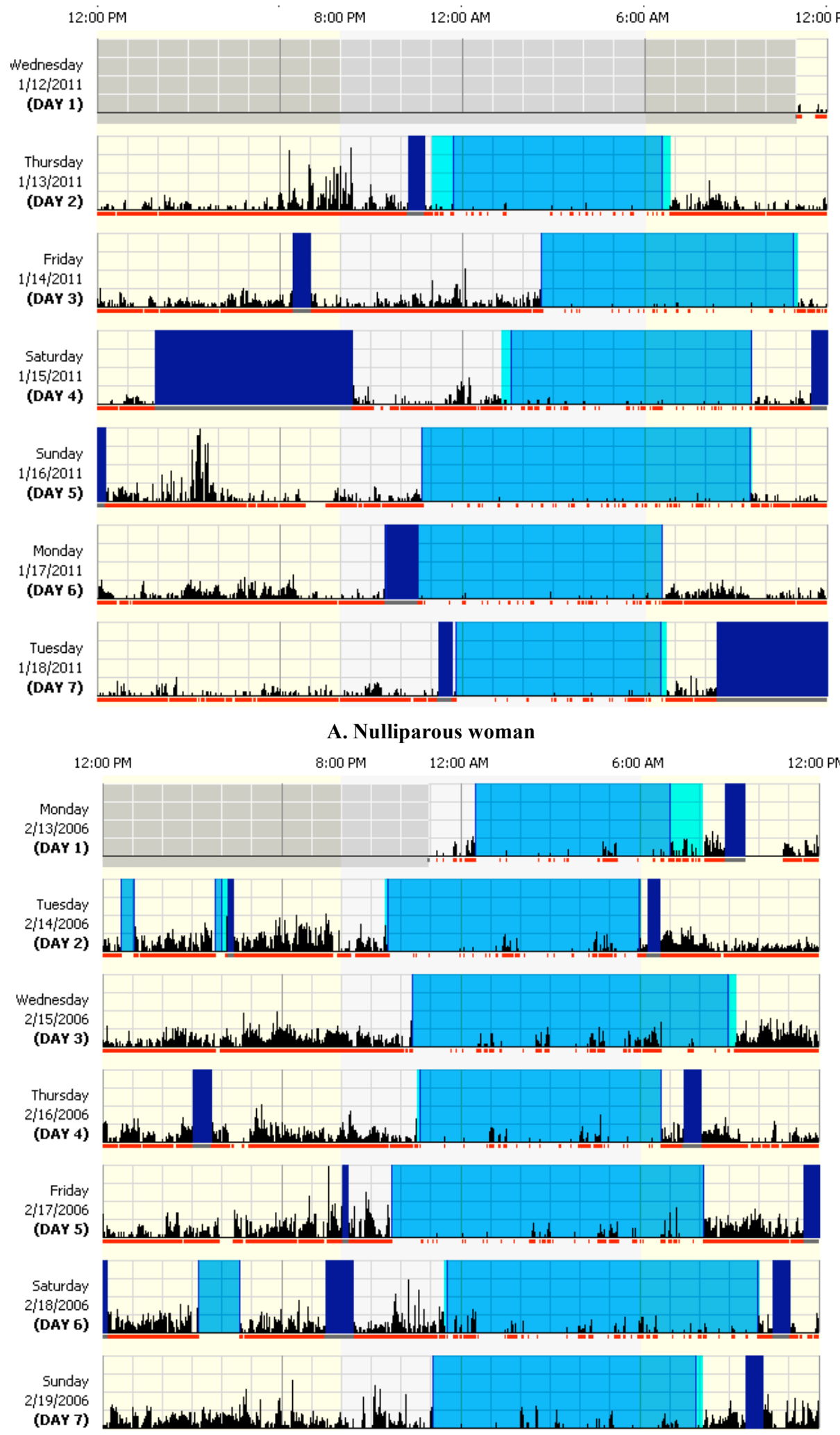

B. Primiparous postpartum woman

Fig. (1). One-week actigraphic tracing for a nulliparous woman (A) age, marital status, and income matched to the primiparous woman (B) at postpartum week 2. On both images, midnight is in the middle, each horizontal rectangle represents one hour, the dark blue sections are when the actigraph was off the participant, and the light blue sections represent her time in bed from sleep onset to sleep offset (corroborated using a sleep diary). These figures illustrate the total sleep time between women did not differ, but their level of sleep efficiency, a measure of sleep fragmentation, was markedly different; the nulliparous woman's sleep was highly consolidated, in contrast to the postpartum woman who experienced high levels of sleep interruption throughout the night and who therefore had to dedicate greater time in bed to achieving the same total sleep time. 
showed that non-depressed women 2-16 weeks had 7.2 hours per night, which did not change significantly across postpartum weeks, while efficiency improved from $79.7 \%$ at week 2 to $90.2 \%$ at week 16 [20]. Postpartum sleep fragmentation is illustrated by Fig. (1).

In a related manner, the specific types of sleep disturbances (e.g., sleep fragmentation and sleep deprivation) experienced are associated with specific daytime conditions and impairments [21, 22]. Specific to postpartum women during the early postpartum period, objectively measured total sleep time was associated with subjective sleepiness; objectively and subjectively measured sleep fragmentation was associated with neurobehavioral performance; and subjective sleep quality was associated with sleepiness and fatigue ratings [22].

Given the evidence thatpostpartum women are sleep disturbed but not necessarily sleep deprived, it makes sense that - despite common advice to "nap when the baby naps" women do not devote much time to daytime napping. In one study, mothers napped on average 0.4-2.0 times per-week, which accounted for 3.13-18.5 minutes of sleep time perweek during the initial postpartum weeks [20], and virtually all napping behaviors ceased after the initial postpartum weeks [20, 23].

\section{SUBJECTIVE SLEEP DISTURBANCE}

Subjective sleep disturbance is common among new mothers, and they report being surprised by their level of disturbance and daytime exhaustion [24]. Our recent work indicates that during the early postpartum period, mothers tend to overestimate their nocturnal wake time when compared to objective measures [22]. An accurate representation of how mothers think they slept is important because their subjective sleep quality predicts subjective daytime sleepiness [22], as well as daytime behaviors such as napping [23]. Most concerning, as sleep disturbance accumulates, which leads to subsequent daytime sleepiness, individuals become less accurate judges of their own levels of sleepiness [25]. Accurate perception of one's own state could have far reaching and dire consequences. For example, if a parent was to perceive himself/herself as less sleepy than he/she really is, he/she may engage in a risk associated task while objectively impaired, thus putting himself/herself (or their family) at undue risk.

Furthermore, postpartum mothers describe their sleep as a "negotiated behavior". In other words, mothers must strategically adjust their sleep schedule to match their newborns'. For mothers, the postpartum period is characterized by twice their usual level of subjective daytime sleepiness, a decrease in sleep efficiency, and three times the number of reported nighttime awakenings compared to during pregnancy [26]. The majority of sleep disturbances are caused by the newborns' sleep and feeding schedules [27]. As previously described, infant sleep cycles are shorter than adults, thus leading to a dyssynchrony among the parent infant dyad. Young infants also have a high metabolic demand, which leads to a high frequency of nocturnal infant feedings that disturb maternal sleep [28]. Additionally, mothers report sleep disturbances that are driven by worry about the baby, sleeping arrangements, and exhaustion from the birth [24].

Postpartum sleep disturbances are also caused by the natural physiological alterations that follow childbirth. In a study where mothers slept away from their infants, maternal sleep disruption continued [29], which may have been due to physiological factors such as various hormonal regulations [30]. Physiologic changes that occur during pregnancy may have significant influences on sleep after birth. For example, throughout pregnancy cortisol, estrogen, and progesterone levels increase: high cortisol is associated with stress and depressive symptoms; high estrogen is associated with less REM sleep, fewer night wakings, longer sleep times, and a decrease in sleep latency; and progesterone has a sedative effect and is known to increase non-REM sleep [30].

The sleep promoting effects of estrogen and progesterone are highest during late pregnancy and decrease immediately after delivery [30, 31]. From a homeostatic viewpoint, the precipitous decrease in these hormones after delivery challenges the body to make up for the absence of their sleep promoting effects during the postpartum period.

\section{CONSEQUENCES OF MATERNAL POSTPARTUM SLEEP DISTURBANCE FOR MATERNAL MENTAL HEALTH}

Most work on the effects of postpartum sleep disruption has focused on maternal postpartum depression [32]. Originally described as "post partum blues syndrome" [33], up to $85 \%$ of women report experiencing the "baby blues" within the first week following childbirth [34], a known risk factor for the onset of postpartum depression [35]. Postpartum depression is diagnosed in $10-15 \%$ of women within the first 4 weeks after delivery $[36,37]$ but may have an onset of up to 2 years after delivery $[38,39]$. This reflects the rate of depression among the female population, but onset during the childbearing years is most common [40-42].

An association between the infant's polyphasic sleep, maternal sleep disturbance, and maternal depression has been consistently reported. The fatigue reported by most women during the initial postpartum period is a major factor contributing to the onset of affect and mood disturbance. Swain and colleagues found that negative mood during the first postpartum week was mediated by the amount of time mothers spent awake at night [43], and fatigue has been shown to co-vary with scores on the Beck Depression Inventory during the first 2 postpartum weeks [44]. "Infant sleep problems" (reported by as many as $46 \%$ of parents) are associated with higher parental depression scores [45]. Fisher and colleagues propose that because fatigue plays such a major role, postpartum affect should be seen as a continuum indistinct from fatigue [46]. This issue is so ubiquitous that in one intervention study, $9 \%$ of women treated for postpartum depression were prescribed hypnotics to eliminate fatigue as a sole cause of mood disturbance [47].

While sleep disruption is consistently linked with the onset of postpartum depression and depressive symptoms, it has been difficult for researchers to disentangle the cause and effect relation between the two [48]. However, some work suggests a causal effect of sleep leading to affect changes. Lee and colleagues used polysomnography pre and 
postpartum and found that at 1 month after delivery a negative affect group had an average of 1.7 fewer hours of sleep per day than during their third trimester, and 1.3 hours less than the positive affect group whose sleep remained unchanged from their third trimester [49].

Researchers have also shown that improving the infant's sleep leads to improvements in maternal depression scores [48, 50]. Dennis and Ross' work strongly implicates sleep disturbance as a precipitating factor for onset of depressive symptoms. The authors recruited women with no history of depressive symptoms prior to pregnancy, during pregnancy, or by 1 week postpartum and found that greater perception of fatigue was related to higher depression scores at 4 and 8 weeks postpartum. At 4 weeks mothers with scores $>12$ were 3 times more likely to report that that their infants did not sleep well, and 6 times more likely to report that their infants sleep pattern did not allow the mother to obtain a "reasonable" amount of sleep. Importantly, the authors also report that at both 4 and 8 weeks postpartum, "not being able to get a break and having a baby that slept less than 60 minutes during the day were significantly associated with depressive symptomatology" [51, p191] indicating that nocturnal sleep is highly important.

Overall, the significant deleterious daytime consequences frequently experienced by new mothers may be similar to the effects of fragmenting sleep disorders. However, although postpartum sleep may resemble profiles of sleep from fragmenting sleep disorders, it is important to note that postpartum sleep is not a disordered state. Rather, postpartum sleep should be considered a normative developmental period. This normative period is belied by profoundly high rates of parent-reported "infant sleep problems" [52], which suggests that there is either an epidemic of sleep dysfunction among the infant population (which we think is unlikely), or that parents may have acquired unreasonable expectations about when and for how long their infant should sleep. Further, we expect that our society's trend away from a culture of extended family may have a duplicative effect. First, without the opportunity to observe others going through this normative lifespan period, this first-hand experience may be parents introduction to the realities of long-term sleep disturbance and its effects on their life in so many domains - including health, cognition, function, and relationships quality. In addition, the lack of extended family may mean that parents do not have the support that would ameliorate some of these impacts.

\section{CONSEQUENCES OF MATERNAL SLEEP DISRUPTION FOR INFANT DEVELOPMENT}

Studies support a link between postpartum sleep and depression, which is in turn strongly associated with an increase in negative infant-parent interactions and adverse infant emotional and cognitive outcomes [53, 54]. Infants of mothers with postpartum depression have more eating and sleeping difficulties, and fewer vocal, visual, and physical interactions with their mother. These infants are more likely to have failure to thrive, reduced cognitive abilities, and greater behavior, emotional, and social problems [55]. Even among non-depressed mothers at 3 months postpartum, fatigue was associated with difficulties in maternal-infant relationships [56]. These women are less likely to continue breastfeeding, to interact with their infant by playing and talking with them [57] or to follow a routine, suggesting that these mothers may benefit from intervention strategies aimed at improving scheduling.

\section{POSTPARTUM PATERNAL SLEEP}

Despite the compelling work on maternal postpartum sleep, little is known about the sleep of postpartum fathers'. There is some evidence that fathers also experience changes in sleep from the prenatal to the postpartum period. In a qualitative study, first-time fathers reported that all daily activities center around the infant's caretaking needs and sleeping times [58]. Furthermore, the sleep time of first-time fathers was significantly lower during the early postpartum period when compared to their sleep time assessed when their partners were at 23 weeks gestation [59].

An examination of first-time parents during the third trimester of pregnancy and postpartum month four revealed that fatigue levels were significantly higher during the postpartum period and did not differ between mothers and fathers [60]. To date, a single study included objective (actigraphy) sleep assessment of first-time fathers. Both mothers and fathers had less sleep, had more self-reported sleep disturbance, and had higher ratings of fatigue during the first month postpartum when compared to their levels during the pregnancy [61]. Interestingly, fathers had less 24hour sleep than mothers during both pregnancy and the postpartum period; however, mothers had more sleep fragmentation than fathers during both assessment times. Overall, postpartum parents have more sleep fragmentation and less total sleep time during the initial postpartum period when compared to their levels during the mother's third trimester. Indeed, our recent work replicated these findings among postpartum parents during the third to eighth postpartum week [62]. In our study, postpartum women had lower total sleep time and higher sleep fragmentation compared to childless control women, and postpartum fathers had higher sleep fragmentation compared to childless control men. To our knowledge, no study has quantified paternal napping behaviors.

\section{CONSEQUENCES OF PATERNAL POSTPARTUM SLEEP DISTURBANCE}

Little is known about the effects of postpartum sleep on new fathers, though much of the postpartum literature emphasizes the need to include fathers $[60,63]$. Nevertheless, important strides have been made to examine the condition of postpartum fathers. For example, the Edinburgh Postnatal Depression Scale was recently validated for men [64]. This measure was used to detect a significant correlation between the incidence of depression symptoms among mother-father dyads [65]. Evidence suggests that new fathers experience postpartum depressive symptoms that are positively associated with infant sleep problems [66]. Our recent work has also extended knowledge about the influence of postpartum sleep disturbance on the condition of new fathers [62]. During the early postpartum period, nulliparous mother and father dyads experienced high levels of objectively measured sleepiness (Multiple Sleep Latency Test), while fathers experienced higher levels than mothers. Postpartum mothers and fathers did not differ on subjective 
sleep quality, sleepiness, or fatigue ratings, but mothers demonstrated worse neurobehavioral performance. Overall, both postpartum mothers and fathers experienced higher levels of sleep disturbance, sleepiness, and sleepinessassociated impairments relative to control women and men, respectively.

\section{CONSEQUENCES OF PATERNAL SLEEP DISRUPTION FOR INFANT DEVELOPMENT}

Fathers' sleep is important because the time that fathers spend with their infants following birth has a positive impact on infant development. Among fathers, an active parental role is important because the time fathers spend with their infants following birth leads to positive infant and child outcomes [67]. Furthermore, when fathers take longer periods of family leave they are more involved in infant caregiving nine months later [68]. Along this line, a study of infant childcare and infant interaction among first-time postpartum mothers and fathers revealed that when both parents were available, mothers spent more time providing care-giving than fathers [69]. Conversely, Fagerskiold [70] conducted a qualitative assessment of the lives of first-time fathers and found that when both parents were home, fathers and mothers equally contributed to infant care-giving. The latter work was conducted among a Scandinavian sample that abides by different social policy than North America.

When parental employment is considered, mothers provide a majority of nocturnal care-giving when they are not working; however, fathers increased their nocturnal caregiving behaviors when mothers returned to work [71]. Our recent mixed methods work indicates the extent to which either the mother or father carries out the majority of the nocturnal care-giving responsibilities [72]. Mothers reported more nocturnal awakenings and wake after sleep onset compared to fathers. The majority of mothers' awakenings were caused by the infant, whereas fathers' were not infantcaused. Mothers reported that during their nocturnal awakenings, they primarily carried out infant feeding, general infant care, and infant changing, respectively. Fathers reported that during their nocturnal awakenings, they were primarily due to passive awakenings, self-care, and for carrying out infant feeding.

Although it has not been investigated, we expect that fathers' nighttime parenting may have a supportive effect by reducing the burden on mothers and thus improving family outcomes. In light of our most recent qualitative findings, mothers do the majority of nocturnal care-giving. There are two possible modes by which to involve fathers more in infant nocturnal care-giving. First, fathers may need to take more of an initiative in conducting nocturnal care-giving responsibilities. Second, mothers may need to feel more comfortable with relinquishing care-giving responsibilities to fathers. A more balanced approach to nocturnal care-giving could be to negotiate and establish strategies to optimize parental sleep while providing necessary infant care [72].

\section{INTERVENTIONS TO IMPROVE POSTPARTUM SLEEP FOR PARENTS}

Most randomized, controlled trials (RCTs) of sleep interventions have focused on changing the infant's sleep either through prevention of infant sleep problems in the first few months post partumor by treating infant sleep problems in the second half of the first postpartum year. Interventions aimed at promoting infant sleep in the early postpartum period [73-77] typically provided parents with information related to infant sleep and suggested strategies aimed at limiting interactions that could lead to unwanted sleep associations, increasing the infant's self-soothing ability, and facilitating day-night entrainment. All these trials found longer, more consolidated sleep periods for infants who received the experimental intervention; all outcomes were based on parent report of infant sleep. Although none of these studies examined the effects of the intervention on parental sleep outcomes, one author did examine effects on parents'stress [74] and found parents who received training related to infant sleep reported significantly fewer life hassles than parents in the control group when the infant was 6-9 weeks old. Parents in the sleep training group also did not experience an increase in life hassles over the first four postpartum months, as was observed in the control group parents.

RCTs conducted with older infants [78-81] were focused on providing parents with information regarding negative sleep associations and the importance of self-soothing ability and strategies to decrease night feeding and waking, including establishing a bedtime routine, controlled crying and gradual removal of parental presence at sleep onset. No advice related to improving parents' sleep was offered. Three of the studies $[78,79,81]$ included maternal sleep outcomes and found reductions in problematic infant sleep behaviors and a concomitant improvement in maternal report of sleep outcomes using select items from, or the entire, Pittsburgh Sleep Quality Index (PSQI) [82].

Hiscock and Wake's [78] RCT evaluated sleep quality in only the final 57 women enrolled in their study (total $\mathrm{n}=156)$. Using two items from the PSQI, at two months postintervention women in the intervention group were significantly more likely than women in the control group to rate their own sleep quality as "very good" and less likely to rate it as "very bad" $\left(\mathrm{X}^{2}=9.93, \mathrm{p}=0.02\right)$ and were more likely to report they had "enough" sleep and less likely to have "not enough sleep" $\left(\mathrm{X}^{2}=8.11, \mathrm{p}=0.04\right)$. PSQI total scores were not reported. Differences in sleep quality between groups were not maintained at the four month postintervention assessment.

In a cluster RCT with 328 mothers at maternal child health centers, Hiscock et al. [28] found fewer intervention group mothers reporting poor sleep quality at three (63\% vs. $72 \%$, adjusted $\mathrm{p}=0.16)$ and five $(52 \%$ vs. $63 \%$, adjusted $\mathrm{p}=0.01)$ months post-randomization and insufficient sleep (34\% vs. $45 \%$, adjusted $\mathrm{p}=0.02$ ) at the five month postrandomization assessment only. The authors did not specify which PSQI items were used for these assessments. Although these women were followed at 17 months postrandomization, no sleep quality data were reported at follow up [83].

In a RCT of an internet-based intervention that included infants and toddlers (age range 6-36 months), Mindell and colleagues [81] reported improvements on the PSQI for maternal sleep onset latency, total sleep time, number of night awakenings, time spent awake at night, and sleep efficiency in women in the intervention groups at one- and 
two-weeks post-intervention. Unfortunately, these analyses were presented as within-group one-way repeated measures ANOVAs rather than between-group comparisons, thereby eliminating the benefits conferred by random assignment to group. Improvements within groups, including the control group, are evident but improvements in sleep outcomes based on experimental condition cannot be determined as the data are presented. However, total PSQI scores were analyzed across groups and at two-weeks post-intervention fewer mothers in the control group $(25.0 \%)$ were good sleepers (PSQI total score $<5$ ) as compared to either of the intervention groups (33.3\% intervention; $47.6 \%$ intervention plus routine; $\left.X^{2}=10.72 ; p=0.005\right)$. Women were reassessed one-year post-intervention [84]; using a single-item from the PSQI there was improvement in global sleep quality compared to baseline but ratings were not as high as at two weeks post-intervention. Again, these follow-up data were examined within-groups only.

Only one study has evaluated the effects of an intervention aimed at helping parents resolve their infant's behavioral sleep problems on both maternal and paternal subjective sleep quality [85]. This one-group, pre-test posttest study conducted with 39 couples found statistically significant improvements on PSQI total scores from baseline (2.2 point decrease, SD $4.1 ; \mathrm{p}<0.000)$ at 6 weeks postintervention; unfortunately data were presented in aggregate form rather than analyzed by gender. Although sleep quality was also measured at 16 weeks post-intervention, those data were not presented so longer-term maintenance of sleep quality improvement is unknown.

From the findings of these studies of infant sleep interventions, improvements in infant sleep problems likely result in improved sleep quality for parents, presumably because parents have more time for, and less disrupted, sleep due to fewer and shorter interruptions for infant care at night. However, the strength of evidence from these reports is limited; only one uncontrolled study examined fathers' sleep, no studies employed objective measures of sleep, and all studies suffered from methodological and reporting problems. There is little evidence of the persistence of improved sleep outcomes for parents beyond the immediate post-intervention study period.

Given that infant and parent sleep are inextricably linked, it is surprising that few trials have offered strategies for improving parents' sleep. This dearth in the literature may be explained by a societal view that parental sleep disruption is an expected, non-modifiable experience of parenthood. Although night-parenting cannot be eliminated, three RCTs [86-88] have included interventions independent from the infant's sleep that could improve parents' sleep.

Lee \& Gay [86] included two samples of parents in a RCT of a modified sleep hygiene intervention designed to reduce parental nighttime disruption. Strategies included proximity of the infant to the maternal bedside for care at night, reducing noise from the infant through use of a white noise machine, and low lighting in the maternal bedroom provided by a night light. These strategies, presented to the experimental group participants in the last month of pregnancy, were expected to make infant care more convenient and less arousing, thereby decreasing parent awakenings due to intermittent infant noise and facilitating parents' return to sleep when awoken. No advice related to infant sleep improvement strategies was given. Two samples of first-time expectant parents were enrolled; women and their partners in stable relationships $(n=118)$ recruited from fee-based childbirth classes and women $(n=122)$ recruited from free prenatal classes and clinics serving low-income women. Using actigraphy and self-report of sleep disturbance using the General Sleep Disturbance Scale (GSDS) [89], parents' sleep was measured over a 48-hour period at both one- and three-months postpartum. In the socioeconomically advantaged sample of women and their partners, there were no differences between the intervention and control groups on any sleep outcomes including nocturnal sleep time, sleep efficiency, or wake time after sleep onset (WASO). In the sample of low-income women, those assigned to the intervention group attained more nocturnal sleep (7.1 hours, SD 1.4 vs. 6.5 hours, SD 1.4; $\mathrm{p}=0.016)$, better sleep efficiency $(80 \%$, SD 10 vs. $75 \%$ SD $12 ; \mathrm{p}=0.024)$, and less WASO (19\%, SD 10 vs. 23\%, SD 12; $\mathrm{p}=0.029$ ) at three months postpartum than women in the control group. Although the intervention was described as focused on reducing the frequency of arousals in addition to their duration, number of night awakenings was not reported. Maternal self-report of sleep disturbance on the GSDS did not differ between groups in either sample. These findings suggest that bedroom environment modifications alone may not improve sleep, particularly in advantaged families. While acceptability of the intervention was found in both samples, low fidelity of use of the interventions in the experimental groups (particularly the white noise machine) and contamination with interventionstrategies in the control groups likely limited ability to detect differences in sleep outcomes between groups. The authors suggest that women and their partners from socioeconomically advantaged backgrounds may have been better able to access advice related to maternal and infant sleep and acquire white noise machines and night lights on their own than the low income group of women whose social and material resources were limited. It may also be that the home environments of the less advantaged group were less conducive to sleep (e.g. noisier, more crowded) so that the modifications made to the bedroom in the experimental group were more beneficial.

Stremler et al. [87] conducted a pilot RCT $(n=30)$ of a behavioral-educational intervention to improve maternal and infant sleep in the early postpartum. With the assumption that maternal and infant sleep are both affected by environmental and social cues and that a mother's sleep is affected by her infant's sleep, a multimodal behavioraleducational intervention was developed to reflect multiple influences and provide information, strategies, and encouragement to increase nighttime sleep and sleep continuity for both mother and infant. First-time mothers in the intervention group received a 45 -minute meeting with a nurse in the immediate postpartum, a written booklet and weekly phone contact to reinforce information and problemsolve.

Topics covered in the one-on-one session and booklet included maternal sleep hygiene (e.g. avoidance of caffeine, keeping bedroom cool, dark and quiet), strategies to make maternal sleep a priority, maternal relaxation techniques (e.g. progressive muscle relaxation, deep breathing), discussion of the challenges of sleep deprivation and parenting, 
information on what to expect from infant sleep and sleep cues, strategies for infant sleep promotion (e.g. stretching length between feedings, bedtime routine) and strategies for promoting infant night-day entrainment and self-soothing. Control group participants received a 10-minute meeting during which only maternal sleep hygiene and basic information about infant sleep was discussed.Using actigraphy to measure maternal and infant sleep, infants in the intervention group woke less often and had longer stretches of sleep and women in the intervention group slept more at night (433 vs. 376 minutes, group difference 57 minutes [95\%CI 6-100 minutes], $2 \mathrm{p}=0.03$ ) and fewer rated their sleep as a problem at 6 -weeks $\left(\chi^{2}=4.82,2 p=0.03\right)$, as compared to the control group.

Based on these promising pilot findings, a large scale RCT ( $n=246)$ was conducted to be adequately powered to detect differences on a greater number of maternal and infant sleep and other health outcomes, to enroll a more diverse sample, and to examine outcomes at 12 weeks postpartum when infants are better able to sleep for a longer uninterrupted period without a feeding [88]. The intervention and control group conditions were slightly modified; control group participants received no information about maternal or infant sleep and telephone contacts were made to both groups at 1,2 and 4 weeks postpartum instead of weekly. No statistically significant differences between the two groups were found on any of the maternal or infant sleep or other outcomes at 6 or 12 weeks post partum. Although women in the larger trial were ethnically diverse with $63 \%$ of women identifying themselves as Caucasian, 20\% Asian and 7\% Black, they were overwhelmingly partnered (97\%), had attained post-secondary education $(90 \%)$, and had a mean age of 32 years. These relative advantages in socioeconomic status and support may explain the lack of effect of the intervention. Indeed, many women in both the intervention and control groups (61\%) sought out information about sleep on their own, and may have been able to implement maternal and infant sleep strategies independently. It also may be that the newborn period is too early to implement maternal and infant sleep strategies, or that the early postpartum period is such a period of great change, role adjustment and sleep debt for families that planning for and consistently implementing sleep strategies is not feasible or is not a priority.

The few examinations of interventions to improve parent sleep provide little support for such strategies in the early postpartum. Families who are socially disadvantaged may benefit most from advice regarding infant and maternal sleep and future interventions should be tested in this population. An exploration of parents' beliefs around infant and parent sleep and their experience of barriers, facilitators and motivations related to implementing sleep strategies would provide insight for development and testing of future interventions studies.

\section{SLEEP AND PARENTS' RELATIONSHIP}

Belsky and Pensky assert that the road to divorce begins with a decline in a women's relationship satisfaction after the birth of her first infant [90]. Slightly less dramatically, Shapiro and colleagues [91] describe the transition to parenthood as having at least a temporary impact on relationship satisfaction [92]. The differences in relationship satisfaction trajectories are strikingly different between postpartum and childless couples. Marital satisfaction among childless couples appears to increase across time, whereas marital satisfaction among new parents declines [93]. There are also differences in relationship stability based on parity. Among both primiparous and multiparous women, Wilkinson [94] found a general postpartum decrease in wellbeingalong with an increase in distress, while primiparous women specifically experienced a greater decrease in relationship satisfaction compared to multiparous women. Meijer and van den Wittenboer [95] report a decrease in relationship satisfaction for both mothers and fathers following the birth of their first child. The catalyst for this decreased relationship satisfaction during the postpartum period appears to be the stress of entering parenthood, rather than the time of being in the relationship [96].

As might be expected, given the context of this review, sleep problems are associated with relationship unhappiness [97]. For example, among a large community sample of women, subjective sleep quality was positively associated with relationship satisfaction [98]. A recent review indicated that postpartum sleep disturbance may impact postpartum relationship satisfaction [99]. Our recent work supported the conclusion of this review, and further extended the understanding of sleep and relationship satisfaction among postpartum parents. Specifically, among both mothers and fathers, objectively measured total sleep time independently predicted relationship satisfaction over and beyond mood disturbance, as well as other objectively and subjectively measured sleep variables [100]. This particular work also demonstrated that new mothers and fathers were poor reporters of their partners' subjective sleep, relationship satisfaction, and mood disturbance. This finding is especially important because accurate partner perceptions are associated with favorable relationship outcomes [101].

Relationship quality and sleep seem to be bi-directionally associated among women; because the marital/partner relationship is the main social context for most adults, and most married adults co-sleep, Troxel and colleagues conclude that sleep may have important implications for this relationship [102]. Most studies of sleep and relationships have focused on how relationship satisfaction is affected by one partner's sleep apnea - or snoring. Particular to new parents, their functioning and relationship with their partner can be directly affected by both their own, as well as their partner's sleep disturbance. Specifically, maternal sleep disturbance has been found to affect fathers' sleep disturbance, and the converse has also been found [95].

From a systems perspective, the implications of marital relationship satisfaction on infant well-being [92] is also tied up with the influence of the infant on the parents' sleep. Nystrom and Ohrling [103] describe new mothers' and fathers' experience as, "living in a new and overwhelming world" (p. 319). Although both first-time mothers and fathers report a decrease in marital satisfaction across the first postpartum year, they also report an increase in their infant care self-efficacy $[60,95]$. Relationship satisfaction is particularly important to consider among postpartum parents because it influences positive mother and father coparenting behaviors towards young infants [104] and generally 
promotes positive health outcomes within relationship dyads [105].

\section{FAMILY SLEEPING LOCATIONS}

The American Academy of Pediatrics [106], National Institute of Child Health and Human Development [107], and the United States Consumer Product Safety Commission [108-109] have made consistent recommendations that safe infant sleep means the infant sleeping in a separate bed in the same room as the mother. Despite this controversial [110] recommendation, the limited research on this topic suggests that infant-parent bedsharing is highly prevalent. One in 10 children between the ages of 2 weeks and 2 years sleep exclusively in the parents' bed, and an additional 5-16\% sleep in the parents' bed at least part of the night $[17,111]$.

It is unknown what proportion of bed sharing in this age range is by choice or by perceived necessity. At the 2009 meeting of the Society for Research in Child Development, Middlemiss and Granger report that maternal salivary cortisol was higher when they were bed sharing with their infant by necessity rather than choice. The relation between infant bed sharing and parental sleep has been entirely uninvestigated. The relatively high proportion of children reported to co-sleep with their parents - despite the professional recommendations - emphasizes the need for research on this topic. Such research should be both scientifically objective, and sensitive to the cultural and family dynamics surrounding this parenting decision [112].

\section{FEEDING METHODS}

Because of its well-established benefits to both the infant and mother [113], any perceived disadvantage of breastfeeding should be carefully evaluated. One obstacle to a woman's decision to breastfeed may be concern about how breastfeeding will affect her sleep. Panchula recommends that, "We will want to reassure her that she will do fine with less sleep (don't we all?) and educate her about the important and very real needs of her infant, who is still an immature being not yet ready to be independent." ([114, p.310]. The growing body of evidence described above emphasizes that mothers may not, in fact, "do fine with less sleep".

Thus, while the benefits of breastfeeding are undisputed, maternal concerns about how her feeding method may affect her sleep deserve empirical answers. Some subjective evidence from maternal diaries of infant sleep suggests that compared to formula-fed infants, breastfed infants have less total sleep time [115-118] and more nighttime awakenings [116-118], though others report no differences on either infant sleep measure $[119,120]$. The single objective (actigraphic) study of infant showed more fragmented infant sleep with increased nocturnal breastfeeding [121].

These cumulative findings are explained by the expectation that because breast milk is thought to be digested more quickly, the breast fed infant will awaken more often. However, the common belief that breast feeding leads to greater maternal sleep disruption is almost entirely untested. Four studies have evaluated this question. Three have used actigraphy and found that breastfeeding mothers spend more time awake during the night, but have no total sleep time differences [61], that breastfeeding mothers slept 40 minutes average more per night [122], and that there were no differences whatsoever [123]. Similar to the Gay et al. study [61], a report based on home polysomnography found that breastfeeding mothers had lower sleep efficiency and more nocturnal awakenings, but no total sleep time difference [124].

Two studies have included subjective sleep disturbance and fatigue reports, which also showed no significant differences between mothers who breastfed compared to those who both breast and formula fed their infant $[61,123]$. The contrast between these negative subjective maternal sleep findings and previous studies showing that mothers report their breast fed infants to awaken more often at night [116-118] are intriguing. Without maternal evidence, it would stands to reason that if the infants awaken more often their mothers would too. It is possible that despite their selfreports, breastfeeding mothers are awakening more often during the night to feed their infants but that they return to sleep more quickly or sleep during feedings, and consequently do not remember these awakenings. Objective actigraphy cannot be used to determine whether this is true since actigraphy is not validated for identifying discrete awakenings.

We submit that if breastfeeding mothers are awakening more often at night, breastfeeding itself may induce a compensatory effect. In other words, if they are awakening more often at night, breastfeeding mothers may return to sleep more quickly and not remember these awakenings. Possible reasons for this may include that they are not exposed to as much ambient light or physical activity required to prepare formula. It is also possible that breastfeeding mothers are sleeping during feedings; Quillin and Glenn [125] report that breastfeeding mothers who cosleep have more sleep than both those who do not co-sleep and formula-feeding mothers.

The notion that breastfeeding may have a soporific effect has some support. Sanchez and colleagues showed that four nucleotides present in breast milk have both strong maternal circadian rhythms and appear to facilitate a "hypnotic action" in the infant [126]. In addition, differences in circulating prolactin are suspected to have a primary role in sleep architecture differences among breast and formula feeding mothers. Prolactin shows a nocturnal peak which is vital for milk production, and is usually associated with facilitation of sleep onset and delta wave activity important for restorative sleep [31].

\section{CONCLUSIONS}

In sum, the body of empirical work on postpartum mothers and, to a more limited extent, postpartum fathers, shows a strong profile of sleep disturbance linked to parental mental health and adverse consequences to infant development. A growing body of research consistently challenges the efficacy of standard advice to avoid any type of infant bedsharing; rather, it may be more advantageous to parents to provide education about how to do so safely. In addition, the impact of infant breastfeeding on maternal sleep does not appear to be deleterious, as once believed. Although the postpartum period should be considered a normative developmental period, early return-to-work 
expectations for new parents are likely the reason for high rates of parent-reported infant sleep problems in our society. Hence the need for evaluation of early intervention strategies, which have thus far received little empirical support. There are plentiful opportunities for future research on the sleep of postpartum families. Priority areas include evaluation of the long-term recovery from postpartum parental sleep disturbance, analyses of typical strategies used by parents to cope with sleep disturbance, microanalysis of cause and effect influences of parent-child nocturnal awakenings, and creative intervention strategies aimed to facilitate healthy parental wellbeing while emphasizing that the child is a developing system in need of nocturnal caregiving.

\section{CONFLICT OF INTEREST}

The authors confirm that this article content has no conflicts of interest.

\section{ACKNOWLEDGEMENTS}

Declared none.

\section{REFERENCES}

[1] Bonnet MH. In: Lenfant C, Ed. Sleep Deprivation. New York, Marcel Dekker, 2005; 103-17.

[2] Wilkinson RT. Sleep deprivation: performance tests for partial and selective sleep deprivation. Prog Clin Psychol 1968; 8: 28-43.

[3] Pilcher JJ, Huffcutt AI. Effects of sleep deprivation on performance: a meta-analysis. Sleep 1996; 19: 318-26.

[4] Freidmann J, Blobus G, Huntley A, Mullaney D, Naitoh P, Johnson L. Performance and mood during and after gradual sleep reduction. Psychophysiology 1977; 14: 245-50.

[5] Thomas RJ, Rosen BR, Stern CE, Weiss JW, Kwong KK. Functional imaging of working memory in obstructive sleepdisordered breathing. J Appl Physiol 2005; 98: 2226-34.

[6] Shamsuzzaman AS, Gersh BJ, Somers VK. Obstructive sleep apnea: implications for cardiac and vascular disease. JAMA 2003; 290: 1906-14.

[7] Ferrillo F, Beelke M, Canovaro P, et al. Changes in cerebral and autonomic activity heralding periodic limb movements in sleep. Sleep Med 2004; 5: 407-12.

[8] Haba-Rubio J, Ibanez V, Sforza E. An alternative measure of sleep fragmentation in clinical practice: the sleep fragmentation index. Sleep Med 2004; 5: 577-81.

[9] Durmer JS, Dinges DF. Neurocognitive consequences of sleep deprivation. Semin Neurol 2005; 25: 117-29.

[10] Downey R, Bonnet MH. Performance during frequent sleep disruption. Sleep 1987; 10: 354-63.

[11] Stepanski EJ. The effect of sleep fragmentation on daytime function. Sleep 2002; 25: 268-76.

[12] Wong KK, Grunstein RR, Bartlett DJ, Gordon E. Brain function in obstructive sleep apnea: results from the Brain Resource International Database. J Integr Neurosci 2006; 5: 111-21.

[13] Moore P, Bardwell WA, Ancoli-Israel S, Dimsdale JE. Association between polysomnographic sleep measures and health-related quality of life in obstructive sleep apnea. J Sleep Res 2001; 10: 303-8.

[14] Franken P. Long-term vs. short-term processes regulating REM sleep. J Sleep Res 2002; 11: 17-28.

[15] Kleitman N. Sleep and Wakefulness. University of Chicago Press: Chicago, 1963.

[16] Montgomery-Downs HE. Normal sleep development in infants and toddlers In: Ivanenko A, Ed. Sleep and Psychiatric Disorders in Children and Adolescents. New York, Infoma Healthcare 2008; 1122.

[17] Montgomery-Downs HE, Gozal D. Prevalence and risk factors for snoring from birth to two years. Sleep Med 2006; 7: 211-9.

[18] Dørheim SK, Bondevik GT, Eberhard-Gran M, Bjorvatn B. Subjective and objective sleep among depressed and non-depressed postnatal women. Acta Psychiatr Scand 2009;119: 128-36.
[19] Posmontier B. Sleep quality in women with and without postpartum depression. J Obstet Gynecol Neonatal Nurs 2008; 37: 722-35.

[20] Montgomery-Downs HE, Insana SP, Clegg-Kraynok MC, Mancini LR. Normative maternal postpartum sleep deprivation and fragmentation. Am J Obstet Gynecol 2010; 203: 465.e1-7.

[21] Franzen PL, Siegle GJ, Buysse DJ. Relationships between affect, vigilance, and sleepiness following sleep deprivation. J Sleep Res. 2008; 17: 34-41.

[22] Insana SP, Stacom E, Montgomery-Downs HE. Actual and perceived sleep: Associations with daytime functioning among postpartum women. Physiol Behav 2010;102: 234-8.

[23] Cottrell L Karraker KH. Correlates of nap taking in mothers of young infants. J Sleep Res 2002; 11: 209-12.

[24] Kennedy HP, Gardiner A, Gay C, Lee KA. Negotiating sleep: a qualitative study of new mothers. J Perinat Neonatal Nurs 2007; 21: 114-22

[25] Vaughn BV, D'Cruz OF. Circadian rhythms in fatigue, alertness, and performance. In: Kryger MH, Roth T, Dement WC, Eds. Principles and Practice of Sleep Medicine.Philadelphia, Elsevier Saunders 2005; 594-601.

[26] Nishihara K, Horiuchi S. Changes in sleep patterns of young women from late pregnancy to postpartum: relationships to their infants' movements. Percept Mot Skills 1998; 87: 1043-56.

[27] Hunter LP, Rychnovsky JD, Yount SM. A selective review of maternal sleep characteristics in the postpartum period. J Obstet Gynecol Neonatal Nurs 2009; 38: 60-8.

[28] Thomas KA, Foreman SW. Infant sleep and feeding pattern: effects on maternal sleep. J Midwifery and Women's Health 2005; 50: 399-404.

[29] Karacan I, Williams RL, Hursch CJ, McCaulley M, Heine MW. Some implications of the sleep patterns of pregnancy for postpartum emotional disturbances. Br J Psychiatry 1969; 115: 929-35.

[30] Manber R, Armitage R. Sex, steroids, and sleep: A review. Sleep 1999; 22: 540-55.

[31] Ross LE, Murray BJ, Steiner M. Sleep and perinatal mood disorders: a critical review. J Psychiatry Neurosci 2005; 30: 247 56 .

[32] Ross LE, Sellers EM, Gilbert Evans SE, Romach MK. Mood changes during pregnancy and the postpartum period: Development of a biopsychosocial model. Acta Psychiatr Scand 2004; 109: 45766.

[33] Yalom ID, Lunde DT, Moos RH, Hamburg DA. Post partum blues syndrome. Arch Gen Psychiat 1968; 18: 16-27.

[34] Kendell RE, McGuire RJ, Connor Y, Cox JL. Mood changes in the first three weeks after childbirth. J Affect Disord 1981; 3: 317-26.

[35] Cox JL, Connor Y, Kendell RE. Prospective study of the psychiatric disorders of childbirth. Br J Psychiatry 1982; 140: 1117.

[36] Boyce P, Stubbs JM. The importance of postnatal depression. Med J Aust 1994; 161:471-2.

[37] O'Hara M, Swain A. Rates and risk of postpartum depression - a meta-analysis. Int Rev Psychiatry 1996; 8: 37-54.

[38] Kendell RE, Wainwright S, Hailey A, Shannon B. The influence of childbirth on psychiatric morbidity.Psychol Med 1976; 6: 297-302.

[39] Cooper PJ, Murray L. Course and recurrence of postnatal depression; evidence for the specificity of the diagnostic concept. Br J Psychiatry 1995; 166: 191-915.

[40] O'Hara MW, Neunaber DJ, Zekoski EM. Prospective study of postpartum depression: prevalence, course, and predictive factors. J Abnorm Psychol 1984; 93: 158-71.

[41] Gotlib IH, Whiffen VE. Depression and marital functioning: an examination of specificity and gender differences. J Abnorm Psychol 1989; 98: 23-30.

[42] Sundstrom IM, Bixo M, Bjorn II, Astrom M. Prevalence of psychiatric disorders in gynecologic outpatients. Am J Obstet Gynecol 2001; 184: 8-13.

[43] Swain AM, O'Hara MW, Starr KR,Gorman LL. A prospective study of sleep, mood, and cognitive function in postpartum and nonpostpartumwomen.Obstet Gynecol 1997; 90: 381-6.

[44] Gardner DL. Fatigue in postpartum women. Appl Nurs Res 1991; 4: $57-62$.

[45] Hiscock H, Wake M. Infant sleep problems and postnatal depression: a community-based study. Pediatrics 2001; 107: 131722. 
[46] Fisher JR, Feekery CJ, Rowe-Murray HJ. Nature, severity and correlates of psychological distress in women admitted to a private mother-baby unit. J Paediatr Child Health 2002; 38: 140-5.

[47] Steinberg SI, Bellavance F. Characteristics and treatment of women with antenatal and postpartum depression. Int $\mathrm{J}$ psychiatry Med 1999; 29: 209-33.

[48] Armstrong KL, Van Haeringen AR, Dadds MR, Cash R. Sleep deprivation or postnatal depression in later infancy: separating the chicken from the egg. J. Paediatr Child Health 1998; 34: 260-2.

[49] Lee K, Zaffke ME, McEnany G. Parity and sleep patterns during and after pregnancy. Obstet Gynecol 2000; 95: 14-8.

[50] Armstrong KL, O'Donnell H, McCallum R, Dadds M. Childhood sleep problems: association with prenatal factors and maternal distress/depression. J Paediatr Child Health 1998; 34: 263-6.

[51] Dennis CL, Ross L. Relationships among infant sleep patterns, maternal fatigue, and development of depressive symptomatology. Birth 2005; 32: 187-93.

[52] Reid GJ, Huntley ED, Lewin DS. Insomnias of childhood and adolescence. Child Adolesc Psychiatr Clin N Am. 2009; 18: 9791000.

[53] Murray L, Cooper P, Hipwell A. Mental health of parents caring for infants. Archives of Women's Mental Health 2003; 6: 71-7.

[54] Paulson JF, Dauber S, Leiferman JA. Individual and combined effects of postpartum depression in mothers and fathers on parenting behavior. Pediatrics 2006; 118: 659-68.

[55] Bell AJ, Land NM, Milne S, Hassanyeh F. Long-term outcome of post-partum psychiatric illness requiring admission. J Affect Disord 1994; 31: 67-70.

[56] Righetti-Veltema M, Conne-Perreard E, Bousquet A, Manzano J. Postpartum depression and mother-infant relationship at 3 months old. Journal of Affective Disorders 2002; 70: 291-306.

[57] McLearn KT, Minkovitz CS, Strobino DM, Marks E, Hou W. Maternal depressive symptoms at 2 to 4 months post partum and early parenting practices. Arch Pediatr Adolesc Med 2006;160: 279-84.

[58] Premberg A, Hellstrom AL, Berg M. Experiences of the first year as a father. Scand J Caring Sci 2008; 22: 56-63.

[59] Condone JT, Boyce P, Corkindale CJ. The first-time fathers study: a prospective study of the mental health and wellbeing of men during the transition to parenthood. Aust N Z J Psychiatry 2004; 38: 56-64.

[60] Elek SM, Hudson DB, Fleck MO. Couples' experiences with fatigue during the transition to parenthood. J Fam Nurs 2002; 8: 221-40.

[61] Gay CL, Lee KA, Lee S. Sleep patterns and fatigue in new mothers and fathers. Biol Res Nurs 2004; 5: 311-8.

[62] Insana SP, Montgomery-Downs HE. Sleep and sleepiness among first-time postpartum parents: A field- and laboratory-based multimethod approach. Dev Psychobiol. 2013; 55(4): 361-72.

[63] Perren S, von Wyl A, Simoni H, Stadlmayr W, Bürgin D, Von Klitzing K. Parental psychopathology, marital quality, and the transition to parenthood. Am J Orthopsychiatry 2003; 73: 55-64.

[64] Matthey S, Barnett B, Kavanagh DJ, Howie, P.Validation of the Edinburgh Postnatal Depression Scale for men, and comparison of item endorsement with their partners. J Affect Dis 2001; 64: 17584.

[65] Soliday E, McCluskey-Fawcett K, O’Brien M. Postpartum affect and depressive symptoms in mothers and fathers. Am J orthopsychiatry 1999; 69: 30-8.

[66] Smart J, Hiscock H. Early infant crying and sleeping problems: A pilot study of impact on parental well-being and parent-endorsed strategies for management. J Pediatr Child Health 2007; 43: 28490.

[67] CabreraNJ,Tamis-LeMonda CS, Bradley RH, Hofferth S, Lamb ME. Fatherhood in the twenty-first century.Child Development 2000; 71: 127-36.

[68] Nepomnyaschy L, Waldfogel J. Paternity leave and fathers' involvement with their young children: Evidence from the American ECLS-B. Community, Work and Family 2007;10: 42753.

[69] Laflamme D, Pomerleau A, Malcuit G. A comparison of fathers' and mothers' involvement in childcare and stimulation behaviors during free-play with their infants at 9 and 15 months. Sex Roles 2002; 47: 507-18.

[70] Fagerskiold A. A change in life as experienced by first-time fathers. Scand J Caring Sci 2008; 22: 64-71.
[71] Jones LC, Heermann JA. Parental division of infant care: contextual influences and infant characteristics. Nurs Res 1992; 41: 228-34.

[72] Insana SP, Garfield CF, Montgomery-Downs HE. "I woke up last night because I had to..." Postpartum nocturnal caregiving. J Pediatric Health Care (In press).

[73] Pinilla T, Birch LL. Help me make it through the night: behavioral entrainment of breast-fed infants' sleep patterns.Pediatr 1993; 91 : 436-44.

[74] Wolfson A, Lacks P, Futterman A. Effects of parent training on infant sleeping patterns, parents' stress, and perceived parental competence. J Consult Clin Psychol 1992; 60: 41-84.

[75] Kerr SM, Sowett SA, Smith LN.Preventing sleep problems in infants: a randomized controlled trial.J Adv Nurs 1996; 24: 938-42.

[76] St James-Roberts I, Sleep J, Morris S, Owen C, Gillham P. Use of a behaviouralprogramme in the first 3 months to prevent infant crying and sleeping problems. J Paediatr Child Health 2001; 37: 289-97.

[77] Symon BG, Marley JE, Martin AJ, Norman ER. Effect of a consultation teaching behaviour modification on sleep performance in infants: a randomised controlled trial. Med J Aust 2005; 182: 215-8.

[78] Hiscock H, Wake M. Randomised controlled trial of behavioural infant sleep intervention to improve infant sleep and maternal mood. BMJ 2002; 324: 1062-65.

[79] Hiscock H, Bayer J, Gold L, Hampton A, Ukoumunne OC, Wake M. Improving infant sleep and maternal mental health: a cluster randomised trial. Arch Dis Child 2007; 92: 952-8.

[80] Mindell JA, Telofski LS, Wiegand B, Kurtz ES. A nightly bedtime routine: impact on sleep in young children. Sleep 2009; 32: 599606.

[81] Mindell JA, DuMond CE, Sadeh A, Telofski LS, Kuklarni N, Gunn E. Efficacy of an internet-based intervention for infant and toddler sleep disturbances.Sleep 2011; 34: 451-8.

[82] Buysse DJ, Reynolds CF 3rd, Monk TH, Berman SR, Kupfer DJ. The Pittsburgh Sleep Quality Index: a new instrument for psychiatric practice and research. Psychiatry Res 1989; 28: 193213.

[83] Hiscock H, Bayer JK, Hampton A, Ukoumunne OC, Wake M.Long-term mother and child mental health effects of a population-based infant sleep intervention: cluster-randomized, controlled trial. Pediatr 2008; 122: e621-e627.

[84] Mindell JA, DuMond CE, Sadeh A, Telofski LS, Kuklarni N, Gunn E. Long-term efficacy of an internet-based intervention for infant and toddler sleep disturbances: one year follow-up.JClin Sleep Med 2011; 7: 507-11.

[85] Hall WA, Clauson M, Carty EM, Janssen PA, Saunders RA. Effects on parents of an intervention to resolve infant behavioral sleep problems. Ped Nurs 2006; 32: 243-50.

[86] Lee KA, Gay CL. Can modifications to the bedroom environment improve the sleep of new parents? Two randomized controlled trials. Res Nurs Health 2010; 34: 7-19.

[87] Stremler R, Hodnett E, Lee K, MacMillan S, Mill C, Ongcangco L, Willan A. A behavioral-educational intervention to promote maternal and infant sleep; a pilot randomized, controlled trial. Sleep 2006; 29: 1609-15.

[88] Stremler R, Hodnett E, Kenton L, et al. Effect of behaviouraleducational intervention on sleep for primiparous women and their infants in early postpartum: multisite randomised controlled trial BMJ 2013; 346 doi: http://dx.doi.org/10.1136/bmj.f1 164

[89] Lee KA. Self-reported sleep disturbances in employed women.Sleep 1992;15:493-498.

[90] Belsky J, Pensky E Marital change across the transition to parenthood. Marriage \& Family Review 1988; 12: 133-56.

[91] Shapiro A, Gottman J, Carrére S. The baby and the marriage: Identifying factors that buffer against decline in marital satisfaction after the first baby arrives. J Family Psychol 2000; 14: 59-70.

[92] Lawrence E, Rothman A, Cobb R, Rothman M, Bradbury T. Marital satisfaction across the transition to parenthood. J Fam Psychol 2008; 22: 41-50.

[93] Schulz M, Cowan C, Cowan P. Promoting healthy beginnings: A randomized controlled trial of a preventive intervention to preserve marital quality during the transition to parenthood. J Consult Clin Psychol 2006; 74: 20-31. 
[94] Wilkinson, R. Changes in psychological health and the marital relationship through childbearing: Transition or process as stressor? Aust J Psychol 1995; 47: 86-92.

[95] Meijer A, van den Wittenboer G. Contribution of infants' sleep and crying to marital relationship of first-time parent couples in the $1 \mathrm{st}$ year after childbirth. J Fam Psychol 2007; 21: 49-57.

[96] Gottman J, Notarius C. Marital research in the 20th century and a research agenda for the 21st century. Fam Process 2002; 41: 15997.

[97] Strawbridge WJ, Shema SJ, Roberts RE. Impact of spouses' sleep problems on partners. Sleep 2004; 27: 527-31.

[98] Troxel WM, Buysse DJ, Hall M, Matthews KA. Marital happiness and sleep disturbances in a multi-ethnic sample of middle-aged women. Behav Sleep Med 2009; 7: 2-19.

[99] Medina S, Magnuson S. Motherhood in the 21st century: Implications for counselors. J Counselin Dev 1009; 87: 90-7.

[100] Insana SP, Costello CR, Montgomery-Downs HE. Perception of partner sleep and mood: Postpartum couples' relationship satisfaction. J Sex Marital Ther 2011; 37: 428-40.

[101] Neff L,Karney B. To know you is to love you: The implications of global adoration and specific accuracy for marital relationships. J Pers Soc Psychol 2005; 88: 480-97.

[102] Troxel WM, Robles TF, Hall MH, Buysse DJ. Marital Quality and the Marital Bed: Examining the Covariation Between Relationship Quality and Sleep. Sleep Med Rev 2007; 11: 389-404.

[103] Nystrom K, Ohrling K. Parenthood experiences during the child's first year: literature review. J Adv Nurs 2004; 46: 319-30.

[104] Schoppe-Sullivan SJ, Mangelsdorf SC, Brown GL, SokolowskiMS.Goodness-of-fit in family context: Infant temperament, marital quality, and early coparenting behavior. Infant Behav Dev 2007; 30: 82-96.

[105] Robles TF, Kiecolt-Tlaser JK. The physiology of marriage: pathways to health. Physiol Behav 2003; 79: 409-16.

[106] American Academy of Pediatrics Task Force on Sudden Infant Death Syndrome. The Changing Concept of Sudden Infant Death Syndrome: Diagnostic Coding Shifts, Controversies Regarding the Sleeping Environment, and New Variables to Consider in Reducing Risk Pediatr 2005; 116: 1245-55.

[107] National Institute of Child Health and Human Development statement on SIDS prevention information available at: http://www.nichd.nih.gov/publications/pubs/BTS_QA_Healthprovi ders.cfm

[108] Scheers NJ, Dayton CM, Kemp JS. Sudden Infant Death With External Airways Covered Case-Comparison Study of 206 Deaths in the United States Arch Pediatr Adolesc Med 1998; 152: 540-7.

[109] Scheers NJ, Rutherford GW, Kemp JS. Where Should Infants Sleep? A Comparison of Risk for Suffocation of Infants Sleeping in
Cribs, Adult Beds, and Other Sleeping Locations. Pediatr 2003; 112: 883-9.

[110] Thoman EB. Co-sleeping, an ancient practice: issues of the past and present, and possibilities for the future. Sleep Med Rev 2006; 10: 407-17.

[111] National Sleep Foundation. Sleep in America Poll available at: www.sleepfoundation.org

[112] McKenna JJ, McDade T. Why babies should never sleep alone: a review of the co-sleeping controversy in relation to SIDS, bedsharing and breast feeding. Paediatr Respir Rev 2005; 6: 13452 .

[113] Wu TC, Chen PH. Health consequences of nutrition in childhood and early infancy. Pediatr Neonatol 2009; 50: 135-42.

[114] Panchula J. Is breastfeeding compatible with obtaining a restful night's sleep? J Hum Lact 2003; 19: 310-2.

[115] Lucas A, St James-Roberts I. Crying, fussing and colic behavior in breast- and -bottle-fed infants. Early Human Dev 1998; 53: 9-18.

[116] Quillin SI. Infant and mother sleep patterns during 4th postpartum week. Issues in Comprehensive Pediatric Nurs 1997; 20: 115-23.

[117] DeLeon CW, Karraker KH. Intrinsic and extrinsic factors associated with night waking in 9-month-old infants. Inf Behav Dev 2007; 30: 596-605.

[118] Schwichtenberg AJM, Poehlmann J. A transactional model of sleep-wake regulation in infants born preterm or low birth weight. J Pediatr Psych 2009; 34: 837-49.

[119] Butte NF, Jensen CL, Moon JK, Glaze DG, Frost JD. Sleep organization and energy expenditure of breast-fed and formula-fed infants. Pediatric Research 1992; 32: 514-9.

[120] Thomas KA. Differential effects of breast- and formula-feeding on preterm infants; sleep-wake patterns. JOGNN 2000; 29: 145-52.

[121] Tikotzky L, de Marcas G, Har-Toov J, Dollberg S, Bar-Haim Y, Sadeh A. Sleep and physical growth in infants during the first 6 months. J Sleep Res 2010; 19: 103-10.

[122] Doan T, Gardiner A, Gay CL, Lee KA. Breast-feeding increases sleep duration of new parents. J Perinat Neonatal Nurs 2007; 21 : 200-6.

[123] Montgomery-Downs HE, Clawges H, Santy E. Infant feeding methods and maternal sleep and daytime functioning. Pediatr 2010; 126: e1562-8.

[124] Blyton DM, Sullivan CE, Edwards N. Lactation is associated with an increase in slow-wave sleep in women. J Sleep Res 2002; 11: 297-303.

[125] Quillin SI, Glenn LL. Interaction between feeding method and cosleeping on maternal-newborn sleep.JObstet Gynecol Neonatal Nurs 2004; 33: 580-8.

[126] Sánchez CL, Cubero J, Sánchez J, et al. The possible role of human milk nucleotides as sleep inducers. Nutr Neurosci 2009; 12: 2-8.

Received: December 01, 2011

(C) Montgomery-Downs et al.; Licensee Bentham Open.

This is an open access article licensed under the terms of the Creative Commons Attribution Non-Commercial License (http://creativecommons.org/licenses/by$\mathrm{nc} / 3.0 /$ ), which permits unrestricted, non-commercial use, distribution and reproduction in any medium, provided the work is properly cited. 